\title{
Analgesia and side effects of codeine phosphate associated with paracetamol vs. paracetamol after the extraction of mandibular third molars: a randomized double-blind clinical trial using the split-mouth model
}

\author{
Matheus Furtado de Carvalho ${ }^{1} \cdot$ Yuri Slusarenko da Silva ${ }^{2}$ (D) $\cdot$ Peter Reher $^{3} \cdot$ Maria da Graça Naclério-Homem $^{4}$
}

Received: 14 April 2020 / Accepted: 22 July 2020

(C) Springer-Verlag GmbH Germany, part of Springer Nature 2020

\begin{abstract}
Purpose To assess the analgesia and side effects of codeine phosphate associated with paracetamol (test medication) as compared to paracetamol (control medication) after the extraction of impacted mandibular third molars.

Materials and methods Forty-seven patients removed the right and left impacted mandibular third molars. After one surgery, patients took the test medication and after the other surgery, they took the control medication. Patients with exacerbated pain were prescribed to use the rescue medication instead of the medication initially administered and were included in the rescue group. They were evaluated for 7 days postoperatively, and the mean score of the visual analogue scale (VAS) of pain between test and control medications was assessed by the Poisson distribution. The side effects of these medications were assessed by the patient's complaints. A $P$ value of $<.05$ was considered to be statistically significant.

Results The mean score of the VAS of pain was not statistically different between test and control medications in the non-rescue group, but it was significantly greater in patients previously using paracetamol in the rescue group. The most common side effects reported in both groups, predominantly in patients using the test medication, were drowsiness, dizziness, and nausea.

Conclusion The use of codeine phosphate associated with paracetamol after the extraction of impacted mandibular third molars is a better choice to control the postoperative pain rather than paracetamol, but with more side effects, which are clinically acceptable.
\end{abstract}

Keywords Codeine phosphate $\cdot$ Paracetamol $\cdot$ Molar, third $\cdot$ Tooth extraction $\cdot$ Pain, postoperative

\section{Introduction}

The extraction of impacted mandibular third molars is the most common procedure performed by oral and maxillofacial

Yuri Slusarenko da Silva

yu.slu@hotmail.com

1 Department of Maxillofacial Surgery, Federal University of Juiz de Fora, Juiz de Fora, Brazil

2 School of Dentistry, UniFG University Center (Faculty of Guanambi), Avenida Pedro Felipe Duarte 4911 São Sebastião, Guanambi, Bahia 46430-000, Brazil

3 School of Dentistry and Oral Health, Griffith University, Griffith, Australia

4 Department of Oral \& Maxillofacial Surgery, Traumatology and Prosthesis, Faculty of Dentistry, University of São Paulo, Sao Paulo, Brazil surgeons. The number of dentists performing this procedure has increased, but they may not be familiarized to treat the exacerbated postoperative pain [1] caused by the surgical trauma to the bone and oral mucosa. The psychological, social, and cultural aspects of patients may also influence the degree of pain, and their complaint must never be neglected [2].

The multimodal analgesia consists of the concomitant administration of two or more medications, and this regimen is very useful in the control of moderate postoperative pain with fewer side effects because of the smaller given dose of each medication [3-8]. In this context, the use of $30 \mathrm{mg}$ of codeine phosphate (weak opioid) associated with $500 \mathrm{mg}$ of paracetamol (acetaminophen) after a tooth extraction will act against the pain stimulus in the central nervous system and peripheral receptors, respectively. However, the lack of studies regarding the side effects of this association may make the establishment of the most effective dose difficult to be implemented [9]. 
Additionally, many professionals in dentistry fear to use codeine, considering it as powerful as morphine.

The present study aims to assess the analgesia and side effects of codeine phosphate $(30 \mathrm{mg}$ ) associated with paracetamol $(500 \mathrm{mg})$ as compared to paracetamol $(500 \mathrm{mg})$ after the extraction of the impacted mandibular third molars.

\section{Materials and methods}

Forty-seven healthy patients aged 21 years on average (30 women and $17 \mathrm{men}$ ), with clinical indications to remove the right and left impacted mandibular third molars, were randomly selected. The positions of these teeth were classified according to Pell and Gregory [10] and Winter [11]. Surgeries were performed under local anesthesia (3.6 $\mathrm{ml}$ of $2 \%$ mepivacaine/ 1:20.000 corbadrine) by the same professional. Patients received a preoperative dose of $8 \mathrm{mg}$ of dexamethasone $1 \mathrm{~h}$ before the procedures to prevent swelling/trismus and waited 21 days between the surgeries.

Immediately after the extraction of one mandibular third molar, they took one capsule of codeine phosphate $(30 \mathrm{mg})$ associated with paracetamol $(500 \mathrm{mg})$, named "test medication." After the extraction of the remaining mandibular third molar, they took one capsule of paracetamol $(500 \mathrm{mg})$, named "control medication." Neither researchers nor patients knew what medication has been prescribed after each procedure (Fig. 1). They were oriented to use the same medication with an interval of $6 \mathrm{~h}$ until pain improvement, and those patients with exacerbated or uncontrolled pain were prescribed to use codeine phosphate $(30 \mathrm{mg})$ associated with paracetamol $(500 \mathrm{mg})$, named "rescue medication," instead of the medication initially administered. These cases were included in the rescue group. On the other hand, patients that did not take the rescue medication were included in the "non-rescue group."

Patients were examined immediately, 2 h, 1 day $(24$ h), 2 days (48 h), 3 days (72 h), 4 days (96 h), 5 days (120 h), 6 days $(144 \mathrm{~h})$, and 7 days $(168 \mathrm{~h})$ after the surgery. The efficacy of analgesia was evaluated through the visual analog scale (VAS) of pain, but we did not consider the data immediately after the surgery due to the residual effect of the local anesthesia. After all surgical procedures, patients were oriented to have a cold and soft diet for $24 \mathrm{~h}$ and to perform normal oral hygiene without the use of antiseptic solutions during all postoperative period. Also, they were requested to place an ice pack for 3 min on the mandibular angle in intervals of $6 \mathrm{~h}$ during the first day postoperatively and to sleep with the head elevated over $72 \mathrm{~h}$ to decrease the soft tissue swelling. The occurrence of postoperative side effects by medications was assessed by the patient's complaints.

After the collection of all data, the medication used in each procedure was revealed.

\section{Statistical analysis}

The mean score from the VAS of pain during the postoperative period was compared between patients taking the test medication and the control medication by the Poisson distribution [12], corrected by the Bonferroni method [13] to check for differences in the postoperative periods. The number of capsules of test, control, and rescue medications consumed in the non-rescue group and rescue group was compared by the Poisson distribution [12]. The frequency of the positions of mandibular third molars $[10,11]$ was assessed by McNemar's test [14]. A $P$ value of $<.05$ was considered to be statistically significant.
Fig. 1 Capsules of codeine phosphate $(30 \mathrm{mg})$ associated with paracetamol $(500 \mathrm{mg})$ and capsules of paracetamol (500 mg). The letter "A" or "B" was attributed to these medications because neither researchers nor patients knew what medication has been prescribed after each procedure

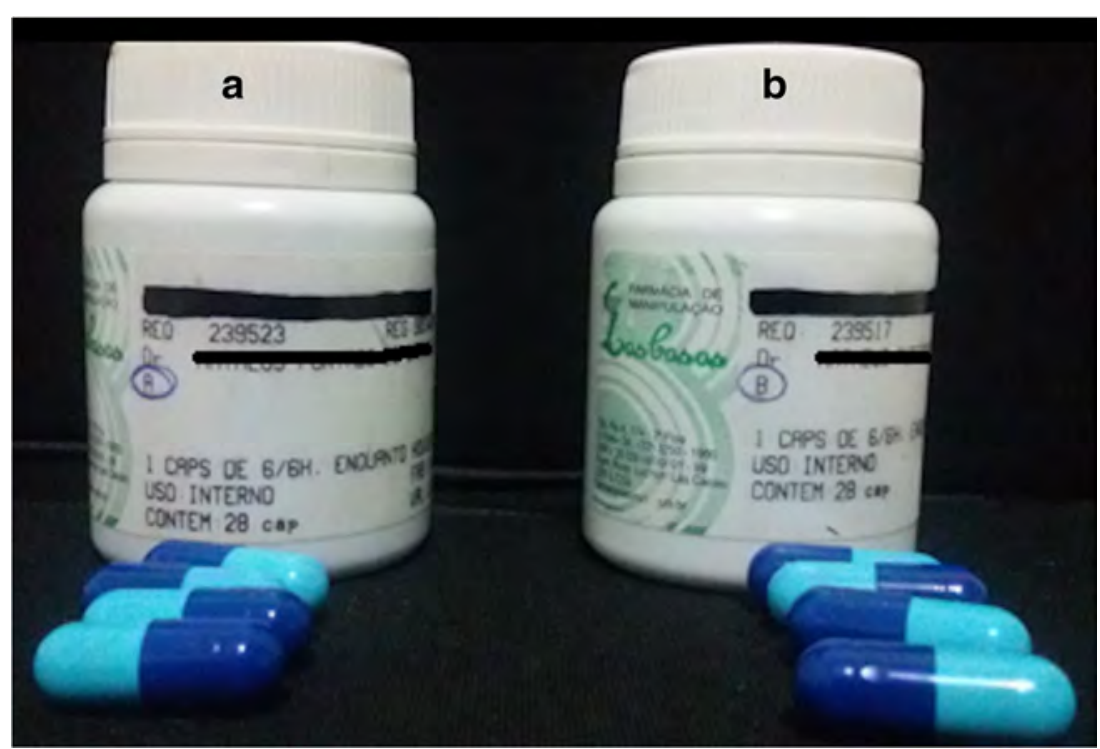


Table 1 Mean score of the VAS of pain in patients using the test medication and the control medication as well as paracetamol + rescue medication

\begin{tabular}{|c|c|c|c|c|}
\hline \multirow{3}{*}{$\begin{array}{l}\text { Postoperative } \\
\text { period (in h) }\end{array}$} & \multicolumn{2}{|c|}{ Non-rescue group } & \multicolumn{2}{|l|}{ Rescue group } \\
\hline & \multicolumn{4}{|c|}{ Mean score of the VAS of pain \pm SD } \\
\hline & $\begin{array}{l}\text { Codeine } \\
\text { phosphate + } \\
\text { paracetamol }\end{array}$ & Paracetamol & $\begin{array}{l}\text { Codeine } \\
\text { phosphate }+ \\
\text { paracetamol }\end{array}$ & $\begin{array}{l}\text { Initially } \\
\text { paracetamol, } \\
\text { changed by } \\
\text { the rescue } \\
\text { medication }^{\text {a }}\end{array}$ \\
\hline 2 & $1.73 \pm 2.24$ & $2.58 \pm 2.44$ & $2.29 \pm 2.63$ & $2.05 \pm 2.22$ \\
\hline 24 & $2.38 \pm 1.92$ & $2.00 \pm 1.60$ & $2.95 \pm 2.09$ & $3.90 \pm 2.86$ \\
\hline 48 & $2.19 \pm 1.92$ & $2.35 \pm 1.60$ & $3.52 \pm 2.46$ & $4.33 \pm 2.24$ \\
\hline 72 & $1.27 \pm 1.99$ & $1.50 \pm 1.18$ & $3.00 \pm 1.95$ & $4.14 \pm 2.27$ \\
\hline 96 & $1.08 \pm 2.02$ & $0.62 \pm 0.90$ & $2.14 \pm 2.27$ & $3.62 \pm 2.54$ \\
\hline 120 & $0.46 \pm 1.03$ & $0.46 \pm 0.71$ & $0.76 \pm 1.34$ & $2.62 \pm 2.64$ \\
\hline 144 & $0.15 \pm 0.61$ & $0.38 \pm 0.98$ & $0.29 \pm 0.90$ & $1.48 \pm 2.64$ \\
\hline 167 & $0.00 \pm 0.00$ & $0.08 \pm 0.39$ & $0.00 \pm 0.00$ & $0.81 \pm 2.18$ \\
\hline
\end{tabular}

$S D$ standard deviation

${ }^{\text {a }}$ Codeine phosphate $(30 \mathrm{mg})+$ paracetamol $(500 \mathrm{mg})$

\section{Results}

Allsurgeriesrequiredosteotomyandtoothsectioning[15] andwere concludedin 17 minonaverage. Nocomplicationsoccurredduring surgeries, buttwocases ofmild alveolarinfection in thenon-rescue group and two cases of mild alveolar infection in the rescue group wereobserved,allofthemoccurring7daysaftertheprocedureandin different patients, with no need for further treatment. Considering the patients individually and according to the classification of Pell andGregory[10]in 100\%ofthecases, bothmandibularthirdmolars showedthesametypeofinclusion, whilein $93.6 \%$ ofthecases, these
teethshowedthesametypeofinclination.AccordingtoWinter[11], in $85.1 \%$ ofthe cases, these teeth presented the sameposition.

Twenty-six patients were included in the non-rescue group. The mean score of the VAS of pain was not statistically different between patients using the test medication and the control medication in all postoperative periods $(P=.42)$. They reported an increased pain between the first and second days after the surgery (Table 1; Fig. 2) and consumed a significantly higher number of paracetamol (18 capsules on average) than codeine phosphate associated with paracetamol (14 capsules of on average) $(P=.001)$. The most common side effects reported in this group, occurring between the first and second days after the surgery, were drowsiness and dizziness, which was predominantly reported in patients using codeine phosphate associated with paracetamol (Table 2).

Twenty-one patients were included in the rescue group, and only those taking paracetamol needed to use the rescue medication. The mean score of the VAS of pain in patients previously using paracetamol was significantly greater in all postoperative periods than in patients using only codeine phosphate associated with paracetamol $(P<.001)$. They reported an increased pain between the first and third days after the surgery $(P<.05)$ (Table 1; Fig. 3$)$ and consumed a significantly higher number of the rescue medication (22 capsules on average) than patients that did not use the rescue medication (17 capsules of codeine phosphate associated with paracetamol on average) $(P=.001)$. Regarding the four cases that developed a mild alveolar infection, observed in the seventh postoperative day, they did not report more pain nor consumed more capsules of medication than the other patients.

The most common side effects reported in this group were drowsiness, occurring between the first and third days after surgeries, and dizziness and nausea, occurring between the third and fourth days after surgeries (Table 2).
Fig. 2 In the non-rescue group, the mean score of the VAS of pain was not statistically different between patients using the test medication and the control medication in all postoperative periods

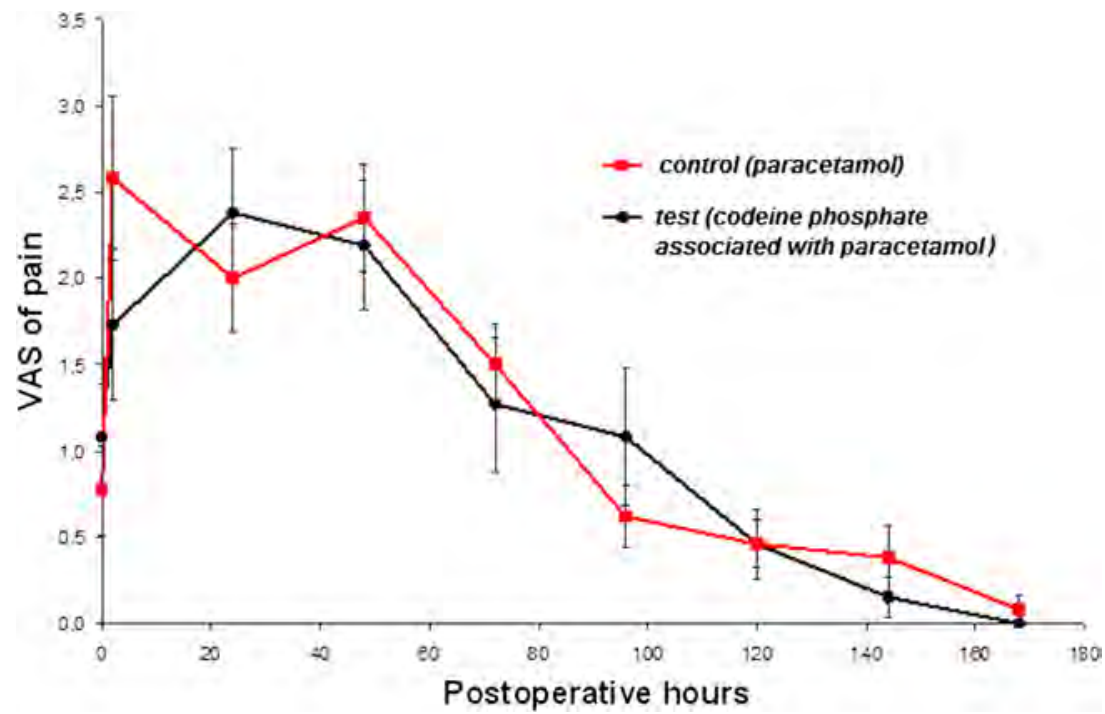


Table 2 Side effects in patients using the test medication and the control medication as well as paracetamol + rescue medication

\begin{tabular}{|c|c|c|c|c|}
\hline \multirow[t]{2}{*}{ Side effect } & \multicolumn{2}{|c|}{$\begin{array}{l}\text { Non-rescue group } \\
\text { Number of patients }(\%)\end{array}$} & \multicolumn{2}{|c|}{$\begin{array}{l}\text { Rescue group } \\
\text { Number of patients (\%) }\end{array}$} \\
\hline & $\begin{array}{l}\text { Codeine } \\
\text { phosphate }+ \\
\text { paracetamol }\end{array}$ & Paracetamol & $\begin{array}{l}\text { Codeine } \\
\text { phosphate + } \\
\text { paracetamol }\end{array}$ & $\begin{array}{l}\text { Initially } \\
\text { paracetamol, } \\
\text { changed by the } \\
\text { rescue } \\
\text { medication }^{\mathrm{a}}\end{array}$ \\
\hline Drowsiness & $10(38.5)$ & 7 (26.9) & $6(28.6)$ & $6(28.6)$ \\
\hline Dizziness & $8(30.8)$ & $1(3.8)$ & $7(33.3)$ & $5(23.8)$ \\
\hline Nausea & $4(15.4)$ & $0(0.0)$ & $4(19.0)$ & $7(33.3)$ \\
\hline Vomit & $2(7.7)$ & $0(0.0)$ & $3(14.3)$ & $2(9.5)$ \\
\hline Hypotension & $1(3.8)$ & $1(3.8)$ & $1(4.8)$ & $2(9.5)$ \\
\hline $\begin{array}{l}\text { Muscle } \\
\text { weakness }\end{array}$ & $2(7.7)$ & $2(7.7)$ & $4(19.0)$ & $3(14.3)$ \\
\hline $\begin{array}{l}\text { Respiratory } \\
\quad \text { depres- } \\
\text { sion }\end{array}$ & $1(3.8)$ & $0(0.0)$ & $0(0.0)$ & $1(4.8)$ \\
\hline Arrhythmia & $0(0.0)$ & $1(3.8)$ & $0(0.0)$ & $0(0.0)$ \\
\hline Euphoria & $2(7.7)$ & $0(0.0)$ & $1(4.8)$ & $1(4.8)$ \\
\hline Constipation & $1(3.8)$ & $1(3.8)$ & $1(4.8)$ & $2(9.5)$ \\
\hline Pruritus & $0(0.0)$ & $0(0.0)$ & $1(4.8)$ & $1(4.8)$ \\
\hline $\begin{array}{r}\text { No side } \\
\text { effect }\end{array}$ & $13(50)$ & 9 (34.6) & $13(61.8)$ & $13(61.8)$ \\
\hline Total & $26(100)$ & $26(100)$ & $21(100)$ & $21(100)$ \\
\hline
\end{tabular}

${ }^{\text {a }}$ Codeine phosphate $(30 \mathrm{mg})+$ paracetamol $(500 \mathrm{mg})$

\section{Discussion}

The extraction of impacted mandibular third molars is a wellestablished study design to evaluate drug therapies for the control of postoperative pain. One of the main advantages of such design is the possibility to conduct researches where the same patient is submitted to test and control treatments, i.e., self-controlled, using the split-mouth technique. However, the skills of the surgeon may interfere in the incidence of postoperative complications, and a surgical time of more than $25 \mathrm{~min}$ will increase the risk of exacerbated postoperative pain [16-18]. In the present study, surgeries lasted $17 \mathrm{~min}$ on average and were technically challenging [15].

The analgesic effects of codeine phosphate associated with paracetamol after the extraction of impacted mandibular third molars seemed to be better than paracetamol alone because 21 patients, which were included in the rescue group, had to abandon the use of paracetamol to use the rescue medication. On the other hand, there was no difference in the mean score of the VAS of pain between patients using the test and control medication in the non-rescue group. Thus, patients from this group were considered to be more resistant to surgical trauma, confirming the theory that psychological, social, and cultural aspects may influence the degree of pain.

Patients consumed a higher number of capsules of paracetamol and rescue medication. In this respect, we can assume that once triggered, the pain stimulus is more difficult to control, and the use of $8 \mathrm{mg}$ of dexamethasone $1 \mathrm{~h}$ before the surgery will also aid in the control of postoperative pain [19]. The authors also observed that patient's recovery was strictly related to the improvement of the swelling, controlled by the use of the corticosteroid [20-22].

According to the mean score of the VAS of pain, the most intense pain occurred between 24 and $48 \mathrm{~h}$ after surgeries in both groups (Table 1; Figs. 2 and 3). The evaluation of the analgesic effects of test and control medications over 7 days is, therefore, of utmost importance to assess the complete postoperative course of the treatment [5-8].

Considering all side effects evaluated, codeine phosphate (30 $\mathrm{mg})$ associated with paracetamol $(500 \mathrm{mg})$ caused more problems than paracetamol $(500 \mathrm{mg})$ in the non-rescue group. Furthermore, the incidence of side effects between test and rescue medications was quite similar in the rescue group. Undoubtedly, codeine phosphate associated with paracetamol will be more problematic to patients in the postoperative period (Table 1), but not enough to discontinue this medication. On the contrary, patients reported that they were more satisfied using the codeine phosphate associated with paracetamol,
Fig. 3 In the rescue group, the mean score of the VAS of pain in patients previously using paracetamol was significantly greater in all postoperative periods than in patients using only codeine phosphate associated with paracetamol

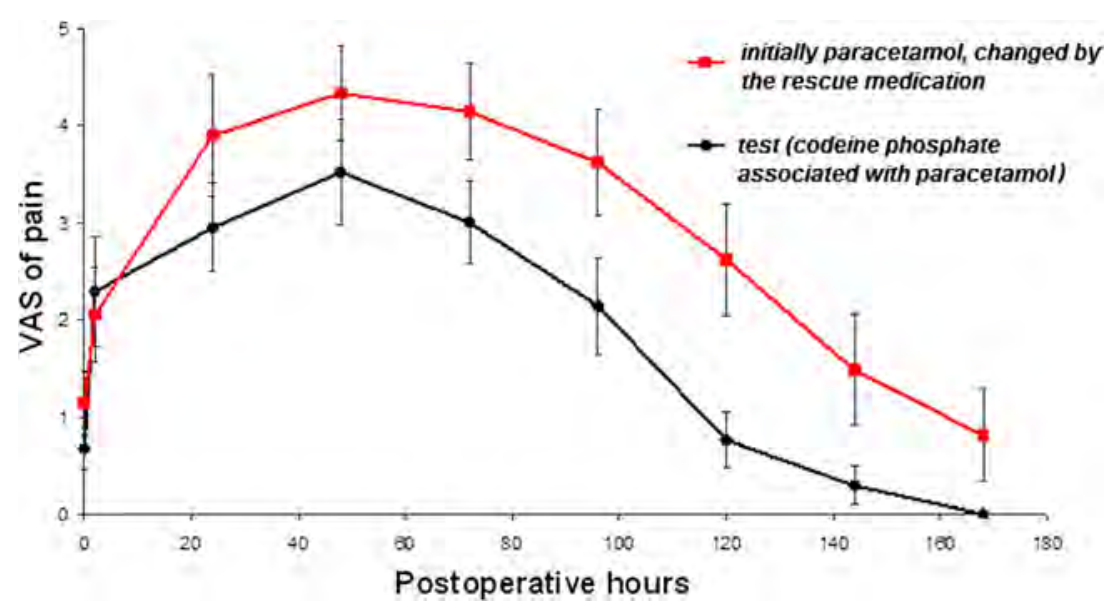


indicating that the pain control is more important than the occurrence of side effects.

The effects of opioids in the central nervous system are not fully understood, but they have been increasingly used to treat cancer patients [23], suggesting the efficacy of this class of medication in the treatment of exacerbated pain. In turn, codeine phosphate is the most common weak opioid associated with other drugs worldwide. In dentistry, codeine phosphate (30 mg) associated with paracetamol (500 mg) will act in synergism with minimal side effects and drug interactions [24].

\section{Conclusion}

Although the analgesia between patients using codeine phosphate $(30 \mathrm{mg})$ associated with paracetamol $(500 \mathrm{mg})$ and paracetamol alone $(500 \mathrm{mg}$ ) was not different in 26 patients, 21 out of 47 patients had to abandon the use of paracetamol to use the rescue medication. Furthermore, patients consumed more paracetamol and rescue medication. Therefore, the use of codeine phosphate associated with paracetamol after the extraction of impacted mandibular third molars is a better choice to control the postoperative pain rather than paracetamol, but with more side effects, which are clinically acceptable.

\section{Compliance with ethical standards}

Conflict of interest The authors declare that they have no conflict of interest.

Ethical approval The present study was approved by the ethics committee of the Faculty of Dentistry of the University of São Paulo (number $317.632 / 2013$ ) and was conducted according to the principles of the Declaration of Helsinki.

Informed consent Written informed consent was obtained from all participants.

\section{References}

1. Sirin Y, Humphris G, Sencan S, Firat D (2012) What is the most fearful intervention in ambulatory oral surgery? Analysis of an outpatient clinic. Int J Oral Maxillofac Surg 41:1284-1290

2. International Association for Study of Pain (IASP). Available from: https://www.iasp-pain.org/index.aspx [Accessibility verified January 9,2020$]$

3. Rosero EB, Joshi GP (2014) Preemptive, preventive, multimodal analgesia: what do they really mean? Plast Reconstr Surg 134:85S-93S

4. Mattia C, Coluzzi F (2015) A look inside the association codeineparacetamol: clinical pharmacology supports analgesic efficacy. Eur Rev Med Pharmacol Sci 19:507-516

5. Jung YS, Kim DK, Kim MK, Kim HJ, Cha IH, Lee EW (2004) Onset of analgesia and analgesic efficacy of tramadol/ acetaminophen and codeine/acetaminophen/ibuprofen in acute postoperative pain: a single-center, single-dose, randomized, active-controlled, parallel-group study in a dental surgery pain model. Clin Ther 26:1037-1045
6. Chang DJ, Bird SR, Bohidar NR, King T (2005) Analgesic efficacy of rofecoxib compared with codeine/acetaminophen using a model of acute dental pain. Oral Surg Oral Med Oral Pathol Oral Radiol Endod 100:74-80

7. Daniels SE, Bandy DP, Christensen SE, Boice J, Losada MC, Liu H, Mehta A, Peloso PM (2011) Evaluation of the dose range of etoricoxib in an acute pain setting using the postoperative dental pain model. Clin J Pain 27:1-8

8. Gatoulis SC, Voelker M, Fisher M (2012) Assessment of the efficacy and safety profiles of aspirin and acetaminophen with codeine: results from 2 randomized, controlled trials in individuals with tension-type headache and postoperative dental pain. Clin Ther 34:138-148

9. Brown JD, Daniels SE, Bandy DP, Ko AT, Gammaitoni A, Mehta A, Boice JA, Losada MC, Peloso PM (2013) Evaluation of multiday analgesia with etoricoxib in a double-blind, randomized controlled trial using the postoperative third-molar extraction dental pain model. Clin J Pain 29:492-498

10. Pell GJ, Gregory GT (1933) Impacted third molars: classification and modified technique for removal. Dent Digest 39:330-338

11. Winter GB (1926) Principles of exodontia as applied to the impacted third molars: a complete treatise on the which clinical diagnosis and radiographics interpretation, 1st edn. American medical books, St Louis

12. McCullagh P, Nelder JA (1989) Generalized linear models, 2nd edn. Chapman and Hall, London

13. Neter J, Kutner MH, Nachtsheim CJ, Wasserman W (1996) Applied linear statistical models, 4th edn. Richard D. Irwing, Ilinois

14. Kirkwood B, Sterne J (2003) Essential medical statistics, 2nd edn. Blackwell Science, Oxford

15. Pozos AJ, Martinez R, Aguirre P, Perez J (2006) The effects of tramadol added to articaine on anesthesia duration. Oral Surg Oral Med Oral Pathol Oral Radiol Endod 102:614-617

16. Jerjes W, Upile T, Nhembe F, Gudka D, Shah P, Abbas S, McCarthy E, Patel S, Mahil J, Hopper C (2010) Experience in third molar surgery: an update. Br Dent J 10:209 E1

17. Seymour RA, Blair GS, Wyatt FAR (1983) Post-operative dental pain and analgesic efficacy. Part I. Br J Oral Surg 21:290-297

18. Lago-Méndez L, Diniz-Freitas M, Senra-Rivera C, GudeSampedro F, Rey JMG, García-García A (2007) Relationships between surgical difficulty and postoperative pain in lower third molar extractions. J Oral Maxillofac Surg 65:979-983

19. Alexander RE, Throndson RR (2000) A review of perioperative corticosteroid use in dentoalveolar surgery. Oral Surg Oral Med Oral Pathol Oral Radiol Endod 90:406-415

20. Alcântara CE, Falci SG, Oliveira-Ferreira F, Santos CR, Pinheiro ML (2014) Pre-emptive effect of dexamethasone and methylprednisolone on pain, swelling, and trismus after third molar surgery: a split-mouth randomized triple-blind clinical trial. Int J Oral Maxillofac Surg 43:93-98

21. Darawade DA, Kumar S, Mehta R, Sharma AR, Reddy GS (2014) In search of a better option: dexamethasone versus methylprednisolone in third molar impaction surgery. J Int Oral Health 6:14-17

22. Chaudhary PD, Rastogi S, Gupta P, Niranjanaprasad Indra B, Thomas R, Choudhury R (2015) Pre-emptive effect of dexamethasone injection and consumption on post-operative swelling, pain, and trismus after third molar surgery. A prospective, double blind and randomized study. J Oral Biol Craniofac Res 5:21-27

23. Kurita GP, Benthien KS, Nordly M, Mercadante S, Klepstad P, Sjøgren P (2015) The evidence of neuraxial administration of analgesics for cancer-related pain: a systematic review. Acta Anaesthesiol Scand 59:1103-1115

24. Mehlisch DR (2002) The efficacy of combination analgesic therapy in relieving dental pain. J Am Dent Assoc 133:861-871

Publisher's note Springer Nature remains neutral with regard to jurisdictional claims in published maps and institutional affiliations. 